\title{
INFLUENCE OF DIFFERENT TYPES OF ANESTHESIA ON THE INFLAMMATO- RY RESPONSE IN LAPAROSCOPIC HYSTERECTOMY
}

\author{
Stanislav Zaychenko, Ruslan Tkachenko
}

The aim of the study was to evaluate the influence of different variants of anesthesia, including low-opioid (LOA) and opioid-free anesthesia (OFA), on the dynamics of the inflammatory response during laparoscopic hysterectomy.

Materials and methods: 102 patients were randomly allocated into 3 groups: 37 women assigned to receive a standard opioid-based anesthesia (OBA group), 33 women - LOA group and 32 patients - OFA group. In the LOA group, the amount of fentanyl was halved and lidocaine infusion and ketamine were additionally infused during induction. In the OFA group, ketamine, lidocaine and dexmedetomidine were additionally infused instead of fentanyl.

Results: Conducting a laparoscopic hysterectomy is accompanied by the activation of the inflammatory process and is manifested by an increase in the content of leukocytes and granulocytes, and a decrease in the number of lymphocytes, which is accompanied by an increase in the leukocyte index of intoxication. These changes were most significant in patients undergoing standard anesthesia. The activation of the inflammatory process is confirmed by an increase in the level of pro-inflammatory IL-6 in all groups from $28.8 \%$ to $92.9 \%$, and it was most pronounced in patients who underwent LOA. In the same group, the greatest increase in the level of anti-inflammatory IL-10 was also noted, the level of which was $115.4 \%$ higher $(p=0.036)$ than in the control group. An increase in the content of the pro-inflammatory cytokine IL-6 in each group and a parallel increase in anti-inflammatory IL-10 in groups 2 and 3, with a simultaneous decrease in it in group 1 led to a significant increase in the IL-6 / IL-10 ratio in the control group. This indicator was significantly higher than in groups 2 and 3 by $42.3 \%(p=0.043)$ and $52.7 \%(p=0.041)$, respectively, while the IL-6 / IL-10 ratio in these groups was not differed from the initial state.

Conclusion: Laparoscopic hysterectomy is accompanied by activation of the inflammatory process and is manifested by an increase in the content of leukocytes and granulocytes and a decrease in the number of lymphocytes, which is accompanied by an increase in the leukocyte index of intoxication. These changes were most significant in patients undergoing standard anesthesia. The use of LOA and OFA is accompanied by a lower activation of the inflammatory response in laparoscopic hysterectomy than in standard anesthesia, but requires further study

Keywords: Inflammatory response, low-opioid anesthesia, opioid-free anesthesia, laparoscopic hysterectomy

\section{How to Cite:}

Zaychenko, S., Tkachenko, R. (2021). Influence of different types of anesthesia on the inflammatory response in laparoscopic hysterectomy. ScienceRise: Medical Science, 2 (41), 17-21. doi: http://doi.org/10.15587/2519-4984.2021.228555

(C) The Author(s) 2021

This is an open access article under the CC BY license (http://creativecommons.org/licenses/by/4.0).

\section{Introduction}

Hysterectomy is one of the most common gynecological surgeries [1], and in recent years, preference is given to laparoscopic methods of its implementation. It is considered the standard of surgical treatment in most women with uterine leiomyoma [2]. The advantages of laparoscopic surgery are obvious. They are: minimal tissue trauma, rapid rehabilitation, no scars. However, despite these obvious advantages of laparoscopic surgery, it is associated with the risk of developing a number of complications in the perioperative period.

Anesthesia of laparoscopic surgeries in gynecology has been the subject of widespread discussion and debate for a long time. In accordance with the concept of safety of endosurgical intervention, the meaning of which is low trauma and good tolerability by the patient, the methods of anesthesia and their safety are improved. In this regard, long-term gynecological surgeries are increasingly performed using endoscopic surgical treatment techniques [3].
Despite advances and progress in medicine and pharmacology, the problem of antinociceptive protection of patients from acute surgical pain, both during and after surgery, remains unresolved in anesthesiology and surgery [4]. Therefore, one of the main directions of development of modern anesthesiology is the treatment of perioperative pain in order to limit the negative consequences of intra- and postoperative pain.

Opioids have been the "gold standard" for perioperative analgesia in most countries for many years. Traditionally, opioids have played a central role in balanced anesthesia, as they help to control nociception and optimize hemodynamics [5], but have many side effects, such as respiratory depression, postoperative nausea and vomiting (PONV), pruritus, constipation, and more. These side effects prolong the patient's stay in the hospital [6].

Opioid-induced respiratory depression is a major cause of opioid mortality [7]. Thus, the side effects of opioids not only increase the incidence of patients 
and worsen the postoperative course, but also increase the cost of medical care [8].

Many publications on new side effects of narcotic analgesics: opioid-induced postoperative hyperalgesia [9], opioid-induced postoperative immunosuppression, and cancer progression [10,11] and opioid-induced decrease in local anesthetics [12] appeared from 2015 to 2020. Thus, opioid-related side effects and the problem of inadequate post-surgical analgesia lead to the search for new methods of anesthesia without the use of opioids or low-opioid anesthesia (LOA), based on a multimodal approach to perioperative analgesia with opioid-free analgesics and adjuvants. It has been established that the use of opioid-free anesthesia (OFA) with non-steroidal anti-inflammatory drugs, dexamethasone, lidocaine and ketamine either reduces or avoids intraoperative and postoperative use of opioids in patients after laparoscopic gynecological operations [13]. Dexmedetomidine has also been shown to provide adequate analgesia in patients undergoing laparoscopic surgery [14].

It is well known that surgical trauma is accompanied by the development of inflammation at the site of surgery, which is aimed at destroying damaged tissues and is the basis of the healing process. Virtually any surgery can cause a secondary immunodeficiency of varying severity. In the perioperative period, immune reactivity is affected by such components of surgical stress as surgical trauma, blood loss, blood transfusions, blood pressure fluctuations, hypothermia, hyperglycemia and postoperative pain. In addition, the level of activity of the body's protective inflammatory mechanisms depends not only on the degree of tissue damage and the level of immunity, but also on certain drug effects, including drugs for anesthesia [15]. The components of surgical stress induce the release of cortisol and catecholamines, which, in turn, interact with the corresponding glucocorticoid and $\beta$ adrenoceptors of monocytes, macrophages and $\mathrm{T}$ lymphocytes, inhibiting the production of Th1lymphocytes by pro-inflammatory Th2-cytokines and ILcytokines, lymphocytes of anti-inflammatory cytokines IL-4 and IL-10 [16]. Although Th2 cytokines normally limit the inflammatory response to surgical injury, their excessive and uncontrolled secretion leads to immunosuppression. Activated monocytes, macrophages and lymphocytes secrete such pro-inflammatory cytokines as IL-1, IL-6, TNF- $\alpha$.

In the light of recent publications and research on the immunosuppressive effects of opioids [11], it is very important to find adequate methods of anesthesia that minimize immunosuppression and the inflammatory response of the body to surgery. The inclusion of ketamine and lidocaine in the complex of components of lowopioid and opioid-free anesthesia, which have a certain anti-inflammatory effect $[17,18]$ is quite promising in this sense. Still, we have not found thorough studies on the effect of LOA and OFA on the inflammatory response. This raises the question of finding an alternative to standard opioid anesthesia in laparoscopic hysterectomy, taking into account its immunosuppressive effect in the postoperative period with appropriate analysis of strategic approaches and search for different options for anesthesia that minimize immunosuppressive effects and inflammatory response.
The aim of the research was to evaluate the influence of different variants of anesthesia, including LOA and OFA, on the dynamics of the inflammatory response during laparoscopic hysterectomy.

\section{Materials and methods}

The work was performed on the basis of Municipal non-profit enterprise "Kyiv City Center of Reproductive and Perinatal Medicine" of the executive body of the Kyiv City Council (Kyiv City State Administration) (Director - Corresponding Member of the National Academy of Medical Sciences of Ukraine, Professor V. V. Kaminskyi) and on the basis of LLC "Citi Doctor" (Director - V. O. Reonov ) during 2017-2020 in compliance with the basic biotic provisions of the Council of Europe Convention on Human Rights and Biomedicine, the Helsinki Declaration of the World Medical Association on the ethical principles of scientific medical research with human participation. The research protocol was approved at the meeting of the commission on biomedical ethics of the National Medical Academy of Postgraduate Education named after P. L. Shupyk (protocol No. 10 of November 20, 2017). All patients signed written informed consents in accordance with the Declaration of Helsinki.

The study involved 102 patients who underwent laparoscopic hysterectomy and who met the criteria for inclusion in the study (age 35 to 65 years and compensated extragenital pathology); physical condition of patients corresponded to class I-II for ASA. Patients with ASA $>$ grade II, body mass index (BMI)> $35 \mathrm{~kg} / \mathrm{m}^{2}$, decompensated extragenital pathology, previous laparotomies, hypersensitivity to drugs used during anesthesia were excluded from the study.

Depending on the variant of anesthesia used, all patients were randomly divided into three groups. The first (control) group included 37 women who underwent standard opioid-based anesthesia (OBA), the second group included 33 patients who underwent low-opioid anesthesia (LOA group), and the third group included 32 patients who received opioid-free anesthesia (OFA group).

The mean age of the examined patients was $47.4 \pm 11.8$ (36-64) years. Body mass index (BMI) was $25.2 \pm 6.3 \mathrm{~kg} / \mathrm{m}^{2}$. Differences in height, weight and age in patients of all groups were not detected (Table 1), which allowed us to consider groups with different methods of analgesia as statistically homogeneous.

Table 1

Demographic and anthropometric indicators in research groups, $\mathrm{M} \pm \mathrm{SD}$

\begin{tabular}{|c|c|c|c|}
\hline Indicator & OBA $(n=37)$ & LOA $(n=33)$ & OFA $(n=32)$ \\
\hline Age, years & $47.4 \pm 11.3$ & $46.6 \pm 9.4$ & $47.6 \pm 8.9$ \\
\hline Height, $\mathrm{cm}$ & $164.5 \pm 6.4$ & $164.4 \pm 8.1$ & $165.8 \pm 4.8$ \\
\hline Weight, kg & $70.2 \pm 13.2$ & $69.3 \pm 9.8$ & $71.7 \pm 14.3$ \\
\hline $\begin{array}{l}\text { Body mass index } \\
\text { (BMI) } \mathrm{kg} / \mathrm{m}^{2}\end{array}$ & $25.4 \pm 4.7$ & $24.9 \pm 3.8$ & $25.5 \pm 6.5$ \\
\hline
\end{tabular}

All surgeries were performed under general anesthesia with mechanical lung ventilation (MLV) and inhalation of sevoflurane $2-2.5 \mathrm{vol} \%$. All patients were ad- 
ministered dexketoprofen $50 \mathrm{mg}$ intravenously 10 minutes before surgery. Propofol $1.5 \mathrm{mg} / \mathrm{kg}$ was used for induction of anesthesia. Tracheal intubation was performed after bolus administration of atracurium besylate $-0.3 \mathrm{mg} / \mathrm{kg}$. Ventilation was performed in the control mode by volume of oxygen-air mixture with a tidal volume of $6-8 \mathrm{ml} / \mathrm{kg}$. Correction of ventilation parameters was carried out according to capnometry to maintain normoventilation with the target level of partial pressure of carbon dioxide on exhalation $\left(\mathrm{PETCO}_{2}\right) 30$ $35 \mathrm{~mm} \mathrm{Hg}$. If necessary, the neuromuscular block was supported by additional administration of atracurium besylate at the dose of $0.15-0.3 \mathrm{mg} / \mathrm{kg}$.

Intra-abdominal pressure at all stages of the operation was maintained in the range of $12-15 \mathrm{~mm} \mathrm{Hg}$.

Protocol of anesthesia in the first (control) group of opioid-based anesthesia: induction - fentanyl $2 \mu \mathrm{g} / \mathrm{kg}+$ propofol $-1.5 \mathrm{mg} / \mathrm{kg}+$ atracurium besylate $0.3 \mathrm{mg} / \mathrm{kg}$, followed by tracheal intubation and mechanical ventilation. Anesthesia was maintained by inhalation of sevoflurane 2.0-2.5 vol. \% and infusion of fentanyl $3-5 \mu \mathrm{g} / \mathrm{kg} /$ per hour.

Protocol of anesthesia in the group of lowopioid anesthesia (group II): induction - fentanyl $2 \mu \mathrm{g} / \mathrm{kg}+$ propofol $-1.5 \mathrm{mg} / \mathrm{kg}+$ atracurium besylate $0.3 \mathrm{mg} / \mathrm{kg}+$ ketamine $12.5 \mathrm{mg}+$ lidocaine $1.0 \mathrm{mg} / \mathrm{kg}$. It was followed with tracheal intubation and mechanical respiration in the normoventilation mode. Anesthesia was maintained by inhalation of sevoflurane $2.0-2.5$ vol. \% and infusion of lidocaine $1.0 \mathrm{mg} / \mathrm{kg} /$ per hour and fentanyl 1.5-2 $\mu \mathrm{g} / \mathrm{kg} /$ per hour. Paracetamol at a dose of $1000 \mathrm{mg}$ was administered intravenously 15 minutes before the end of the surgery.

Anesthesia protocol in the group of safe anesthesia (group III): gabapentin $600 \mathrm{mg} 2$ hours before surgery; nefopam $20 \mathrm{mg} /$ intramuscularly 10 minutes before surgery + lidocaine $1.0 \mathrm{mg} / \mathrm{kg}+$ infusion of dexmedetomidine $1.0 \mu \mathrm{g} / \mathrm{kg}+$ dexamethasone $-8 \mathrm{mg}$. Induction: propofol $-1.5 \mathrm{mg} / \mathrm{kg}+$ atracurium besylate $0.3 \mathrm{mg} / \mathrm{kg}+$ ketamine $12.5 \mathrm{mg}$, followed by tracheal intubation and mechanical lungs ventilation. Anesthesia was maintained by inhalation of sevoflurane $2.0-2.5$ vol. \% and infusion of ketamine $0.5 \mathrm{mg} / \mathrm{kg} / \mathrm{h}$, lidocaine $1.0 \mathrm{mg} \mathrm{/} \mathrm{kg} \mathrm{/} \mathrm{per} \mathrm{hour} \mathrm{and} \mathrm{dexmedetomidine}$ $0.6 \mu \mathrm{g} / \mathrm{kg} /$ per hour. Paracetamol - $1000 \mathrm{mg}$ was administered intravenously 15 minutes before the end of the surgery.
The number of leukocytes, granulocytes, lymphocytes was determined to evaluate the severity of the inflammatory process and immune reactions that accompany surgical trauma, using an automatic hematology blood analyzer MicroCC-20Plus (USA). The leukocyte formula and the leukocyte intoxication index (LII) were calculated manually. LII was calculated according to the formula worked out by Ya.Ya. Kalf-Khalif (1941) [19]. Normally, LII is $0.3-1.5$.

Also in the perioperative period, the dynamics of circulating cytokines (IL-6, IL-10) and their ratios as markers of systemic inflammatory and anti-inflammatory response were studied. Serum cytokine levels were determined by enzyme-linked immunosorbent assay (ELISA) on an automatic enzyme-linked immunosorbent assay (Lazurite) (Dynex Technologies Inc., USA) using standard reagent kits (Human IL-6, Human IL-10, Bender MedSystems GmbH, Austria), respectively to the manufacturer's instructions. The study was performed in the dynamics - before surgery and 24 hours after surgery.

Descriptive and analytical biostatistics methods were used for statistical processing of research materials. Under the normal distribution law, parametric characteristics and methods of analysis were used: arithmetic mean (M) and standard deviation (SD). Evaluation of the reliability of differences between groups was performed on the basis of parametric analysis of variance ANOVA and nonparametric Kraskel-Wallis test. Differences were considered statistically significant under the condition of statistical error, which did not exceed $5 \%(p<0.05)$.

Statistical analysis of the obtained data was performed using the software package Statistica for Windows 6.1 (Statsoft Inc., USA).

\section{Research results}

Analysis of changes in inflammatory response found that on the first day after surgery in patients of $1^{\text {st }}$ (control) group there was an increase in the number of leukocytes by $16.4 \%(p=0.024)$ and LII by $190.4 \%$ $(p<0.001)$ compared with pre-surgery level (Table 2). The increase in LII was due to an increase in the content of granulocytes, the number of which significantly increased by $18.7 \%$ and a decrease in the content of lymphocytes by $28.2 \%(p=0.029)$. The detected changes indicated the activation of inflammatory processes in response to surgical trauma in patients who underwent standard opioid-based anesthesia.

Table 2

Dynamics of leukocyte content at the stages of the study depending on the type of anesthesia, $\mathrm{M} \pm \mathrm{SD}$

\begin{tabular}{|c|c|c|c|c|c|c|c|c|}
\hline \multirow{2}{*}{$\begin{array}{l}\text { Grou } \\
\text { ps }\end{array}$} & \multicolumn{8}{|c|}{ Indicator } \\
\hline & \multicolumn{2}{|c|}{ Leukocytes, $\times 10^{9} / 1$} & \multicolumn{2}{|c|}{ Granulocytes, \% } & \multicolumn{2}{|c|}{ Lymphocytes, \% } & \multicolumn{2}{|c|}{ LII, conventional units } \\
\hline $\begin{array}{l}\text { Sta } \\
\text { ges }\end{array}$ & $\begin{array}{l}\text { Before } \\
\text { surgery }\end{array}$ & $\begin{array}{l}24 \text { hours } \\
\text { after surgery }\end{array}$ & $\begin{array}{l}\text { Before } \\
\text { surgery }\end{array}$ & $\begin{array}{l}24 \text { hours } \\
\text { after sur- } \\
\text { gery }\end{array}$ & $\begin{array}{l}\text { Before } \\
\text { surgery }\end{array}$ & $\begin{array}{l}24 \text { hours } \\
\text { after sur- } \\
\text { gery }\end{array}$ & $\begin{array}{l}\text { Before } \\
\text { surgery }\end{array}$ & $\begin{array}{c}24 \text { hours } \\
\text { after } \\
\text { surgery }\end{array}$ \\
\hline 1 & \multirow{3}{*}{$6.1 \pm 0.5$} & $7.1 \pm 0.8 *$ & \multirow{3}{*}{$65.2 \pm 7.9$} & $73.6 \pm 8.9^{*}$ & \multirow{3}{*}{$30.9 \pm 5.6$} & $22.2 \pm 3.9 *$ & \multirow{3}{*}{$0.94 \pm 0.42$} & $2.73 \pm 0.87 *$ \\
\hline 2 & & $6.9 \pm 0.4^{*}$ & & $71.1 \pm 7.8$ & & $24.7 \pm 4.2^{*}$ & & $2.01 \pm 1.01^{*}$ \\
\hline 3 & & $6.7 \pm 0.6$ & & $72.8 \pm 11.1$ & & $22.1 \pm 5.7^{*}$ & & $1.76 \pm 0.55^{*}$ \\
\hline Int & oup p & $p>0.05$ & & $p>0.05$ & & $p>0.05$ & & $p_{1-3}=0.048$ \\
\hline
\end{tabular}

Remark. ${ }^{*}-p<0.05$ compared with the pre-surgery stage 
Similar dynamics of changes in the indicators of the inflammatory response was observed in patients of the LOA group (Table 2). Thus, on the first day after surgery there was an increase in the number of leukocytes by $13.1 \%(p=0.041)$, and LII exceeded the norm by $113.8 \%(p<0.001)$. The increase in LII, as in the control group, was due to an increase in the content of granulocytes, the number of which increased significantly by $9.0 \%$ and a decrease in lymphocytes by $20.1 \%$ $(p=0.042)$, which indicated some activation of inflammatory processes in response for surgical trauma.

The study of the dynamics of changes in inflammatory response in patients of the OFA group showed that in contrast to patients in groups 1 and 2, on the first day after surgery there were no statistically significant changes in the number of leukocytes. The content of leukocytes had an insignificant tendency to increase by $11.6 \%(\mathrm{p}=0.076)$, and LII exceeded the norm by $87.2 \%$ $(p<0.001)$. The increase in LII was due to a decrease in lymphocytes by $29.5 \%(p=0.037)$, which indicated some activation of inflammatory processes in response to surgical trauma in patients in this group.

Comparative analysis of leukocyte dynamics and changes in leukocyte formula in different groups showed that the pre-surgery condition of patients was character- ized by no inflammation and the formation of lowintensity inflammation in a day after surgery and did not depend on the variant of anesthesia (Table 2). In all groups, there was an increase in the levels of leukocytes and granulocytes and a decrease in the number of lymphocytes, which, however, had no clinical significance and did not exceed the reference values. Due to the increase in the number of granulocytes and a decrease in lymphocytes, there was an increase in LII from $87.2 \%$ $(p<0.001)$ to $190.4 \%(p<0.001)$ compared with the presurgery condition, and the most significant increase in LII was observed in patients of the control group up to $2,73 \pm 0.87$ conventional units, which was significantly higher by $55.1 \%(p=0.048)$ than in patients of group 3 , which indirectly indicates the lowest activation of the inflammatory response in patients undergoing opioid-free anesthesia.

Intergroup analysis of the dynamics of changes in the cytokines content on the first post-surgical day showed that there was an increase in the level of proinflammatory IL-6 from $28.8 \%$ to $92.9 \%$ in all comparison groups and that fact depended on the type of anesthesia. The most significant increase in IL-6 was observed in patients who underwent LOA and was significantly higher than in the control group ( $p=0.044)$ (Table 3).

Table 3

Dynamics of cytokines at the stages of the study depending on the type of anesthesia, $\mathrm{M} \pm \mathrm{SD}$

\begin{tabular}{|c|c|c|c|c|c|c|}
\hline \multirow{2}{*}{ Groups } & \multicolumn{6}{|c|}{ Indicator } \\
\hline & \multicolumn{2}{|c|}{ IL-6, pg/ml } & \multicolumn{2}{|c|}{ IL-10, pg/ml } & \multicolumn{2}{|c|}{ IL-6 / IL-10 } \\
\hline Stages & $\begin{array}{l}\text { Before sur- } \\
\text { gery }\end{array}$ & $\begin{array}{c}24 \text { hours after } \\
\text { surgery }\end{array}$ & $\begin{array}{c}\text { Before sur- } \\
\text { gery }\end{array}$ & $\begin{array}{c}24 \text { hours after } \\
\text { surgery }\end{array}$ & $\begin{array}{l}\text { Before sur- } \\
\text { gery }\end{array}$ & $\begin{array}{c}24 \text { hours after } \\
\text { surgery }\end{array}$ \\
\hline 1 & \multirow{3}{*}{$1.56 \pm 0.38$} & $2.01 \pm 0.47^{*}$ & \multirow{3}{*}{$3.03 \pm 1.41$} & $2.34 \pm 1.19$ & \multirow{3}{*}{$0.52 \pm 0.15$} & $0.84 \pm 0.22 *$ \\
\hline 2 & & $3.01 \pm 0.72 *$ & & $5,04 \pm 1.79 *$ & & $0.59 \pm 0.21$ \\
\hline 3 & & $2.17 \pm 0.85$ & & $3.94 \pm 1.12$ & & $0.55 \pm 0.24$ \\
\hline \multicolumn{2}{|c|}{ Intergroup $\mathrm{P}$} & $p_{1-2}=0.044$ & & $p_{1-2}=0.036$ & & $\begin{array}{l}p_{1-2}=0.023 \\
p_{1-3}=0.041\end{array}$ \\
\hline
\end{tabular}

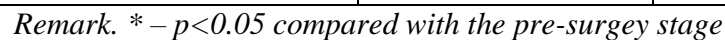

\section{Discussion of research results}

The dynamics of changes in the levels of antiinflammatory IL-10 in different groups was quite interesting. The analysis showed that the level of antiinflammatory IL-10 changed statistically significantly during the study stages within the groups and depended on the type of anesthesia. In patients who underwent standard anesthesia 24 hours after surgery, there was a decrease in IL-10 by $22.8 \%(p=0.469)$ in comparison with pre-surgery levels, while in women from $2^{\text {nd }}$ and $3^{\text {rd }}$ groups, its content increased by $66.3 \%(p=0.039)$ and $30.0 \% \quad(p=0.378)$, respectively. The most significant increase in the level of anti-inflammatory IL-10 was observed in patients of the LOA group and was significantly higher by $115.4 \%(p=0.036)$ than in the control group.

The increase in the content of pro-inflammatory cytokine IL- 6 in all groups and the parallel increase in anti-inflammatory IL-10 in groups 2 and 3, with a simultaneous decrease in group 1 led to a significant increase in the ratio of IL-6 / IL-10 in the control group. This figure was significantly higher than in groups 2 and 3 by
$42.3 \%(\mathrm{p}=0.043)$ and by $52.7 \%(\mathrm{p}=0.041)$, respectively, while the ratio of IL-6 / IL-10 in these groups did not differ from the initial state. This fact may be related to a certain anti-inflammatory effect of ketamine and lidocaine, which were infused in groups 2 and 3, which coincides with the studies of S. Van der Wal et al. (2015) [17] and E.M. to Vale et al. (2016) [18].

\section{Conclusions}

1. Laparoscopic hysterectomy is accompanied by the inflammatory process activation and is manifested by an increase in the content of leukocytes and granulocytes and a decrease in the number of lymphocytes, which is accompanied by an increase in the leukocyte index of intoxication. These changes were most significant in patients undergoing standard anesthesia.

2. Activation of the inflammatory process is confirmed by an increase in the level of pro-inflammatory IL-6 in all groups from $28.8 \%$ to $92.9 \%$ and was most pronounced in patients who underwent low-opioid anesthesia. In the same group there was the greatest increase in the level of anti-inflammatory IL-10, the level of 
which was higher by $115.4 \%(\mathrm{p}=0.036)$ than in the control group.

3. The use of low-opioid and opioid-free anesthesia is accompanied by less activation of the inflammatory response in laparoscopic hysterectomy than standard anesthesia, which may be associated with the anti- inflammatory effects of ketamine and lidocaine, but requires further detailed study.

\section{Conflict of interests}

The authors declare that they have no conflicts of interest.

\section{References}

1. Obermair, A., Armfield, N. R., Graves, N., Gebski, V., Hanna, G. B., Coleman, M. G. et. al. (2019). How to train practising gynaecologists in total laparoscopic hysterectomy: protocol for the stepped-wedge IMAGINE trial. BMJ Open, 9 (5), e027155. doi: http://doi.org/10.1136/bmjopen-2018-027155

2. Chambers, L. M., Carr, C., Freeman, L., Jernigan, A. M., Michener, C. M. (2019). Does surgical platform impact recurrence and survival? A study of utilization of multiport, single-port, and robotic-assisted laparoscopy in endometrial cancer surgery. American Journal of Obstetrics and Gynecology, 221 (3), 243.e1-243.e11. doi: http://doi.org/10.1016/j.ajog.2019.04.038

3. Kireev, S. S., Matveev, A. F., Tupikin, IU. V., Kiselev, A. V. (2017). Features of anesthesiological supports in operations in gynecology. Vestnik novykh meditsinskikh tekhnologii, 2, 175-179.

4. Ovechkin, A. M., Iavorovskii, A. G. (2019). Bezopioidnaia analgeziia v khirurgii: ot teorii k praktike. Mosocow: GEOTAR-Media, 240.

5. Egan, T. D. (2019). Are opioids indispensable for general anaesthesia? British Journal of Anaesthesia, 122 (6), e127-e135. doi: http://doi.org/10.1016/j.bja.2019.02.018

6. White, P. F. (2002). The Role of Non-Opioid Analgesic Techniques in the Management of Pain After Ambulatory Surgery. Anesthesia \& Analgesia, 94 (3), 577-585. doi: http://doi.org/10.1097/00000539-200203000-00019

7. Gupta, K., Nagappa, M., Prasad, A., Abrahamyan, L., Wong, J., Weingarten, T. N., Chung, F. (2018). Risk factors for opioid-induced respiratory depression in surgical patients: a systematic review and meta-analyses. BMJ Open, 8 (12), e024086. doi: http://doi.org/10.1136/bmjopen-2018-024086

8. Pizzi, L. T., Toner, R., Foley, K., Thomson, E., Chow, W., Kim, M. et. al. (2012). Relationship Between Potential OpioidRelated Adverse Effects and Hospital Length of Stay in Patients Receiving Opioids After Orthopedic Surgery. Pharmacotherapy: The Journal of Human Pharmacology and Drug Therapy, 32 (6), 502-514. doi: http://doi.org/10.1002/j.1875-9114.2012.01101.x

9. Lavand'homme, P., Estebe, J. P. (2018). Opioid-free anesthesia a different regard to anesthesia practice. Current Opinion in Anaesthesiology, 31 (5), 556-561. doi: http://doi.org/10.1097/aco.0000000000000632

10. Aich, A., Gupta, P., Gupta, K. (2016). Could Perioperative Opioid Use Increase the Risk of Cancer Progression and Metastases? International Anesthesiology Clinics, 54 (4), e1-e16. doi: http://doi.org/10.1097/aia.0000000000000112

11. Lee, J. S.-J., Hu, H. M., Edelman, A. L., Brummett, C. M., Englesbe, M. J., Waljee, J. F. et. al. (2017). New Persistent Opioid Use Among Patients With Cancer After Curative-Intent Surgery. Journal of Clinical Oncology, 35 (36), 4042-4049. doi: http://doi.org/10.1200/jco.2017.74.1363

12. Liu, Q., Gold, M. S. (2016). Opioid-induced Loss of Local Anesthetic Potency in the Rat Sciatic Nerve. Anesthesiology, 125 (4), 755-764. doi: http://doi.org/10.1097/aln.0000000000001239

13. Hakim, K. K., Wahba, W. B. (2019). Opioid-free total intravenous anesthesia improves postoperative quality of recovery after ambulatory gynecologic laparoscopy. Anesthesia: Essays and Researches, 13 (2), 199-203. doi: http://doi.org/10.4103/aer.aer_74_19

14. Tufanogullari, B., White, P. F., Peixoto, M. P., Kianpour, D., Lacour, T., Griffin, J. et. al. (2008). Dexmedetomidine Infusion During Laparoscopic Bariatric Surgery: The Effect on Recovery Outcome Variables. Anesthesia \& Analgesia, 106 (6), $1741-$ 1748. doi: http://doi.org/10.1213/ane.0b013e318172c47c

15. Popko, I. Yu., Dmytriiev, D. V. (2017). Zminy imunolohichnoï reaktyvnosti orhanizmu pid chas khirurhichnoho vtruchannia ta v pisliaoperatsiy̆nomu periodi zalezhno vid skhemy znebolennia. Pain Medicine Journal, 2 (1), $28-33$.

16. Elenkov, I. J., Chrousos, G. P. (2002). Stress Hormones, Proinflammatory and Antiinflammatory Cytokines, and Autoimmunity. Annals of the New York Academy of Sciences, 966 (1), 290-303. doi: http://doi.org/10.1111/j.1749-6632.2002.tb04229.x

17. Van Der Wal, S., Vaneker, M., Steegers, M., Van Berkum, B., Kox, M., Van Der Laak, J. et. al. (2014). Lidocaine increases the anti-inflammatory cytokine IL-10 following mechanical ventilation in healthy mice. Acta Anaesthesiologica Scandinavica, 59 (1), 47-55. doi: http://doi.org/10.1111/aas.12417

18. Do Vale, E. M., Xavier, C. C., Nogueira, B. G., Campos, B. C., de Aquino, P. E. A., da Costa, R. O. et. al. (2016). Antinociceptive and Anti-Inflammatory Effects of Ketamine and the Relationship to Its Antidepressant Action and GSK3 Inhibition. Basic \& Clinical Pharmacology \& Toxicology, 119 (6), 562-573. doi: http://doi.org/10.1111/bcpt.12637

19. Kalf-Kalif, Ia. Ia. (1941). O leikotsitarnom indekse intoksikatsii i ego prakticheskom znachenii. Vrachebnoe delo, 1, 31-35.

Received date 02.12.2020

Accepted date 05.01.2021

Published date 31.03.2021

Stanislav Zaychenko, Doctor, Department of Anesthesiology \& Intensive Care, Kyiv City Center for Reproductive and Perinatal Medicine, Heroiv Stalinhradu ave., 16, Kyiv, Ukraine, 04210

E-mail: zaychenkostanislav@gmail.com

Ruslan Tkachenko, MD, Professor, Department of Obstetrics, Gynecology and Reproductology, Shupyk National Healthcare University of Ukraine, Dorohozhytska str., 9 Kiyv, Ukraine, 04112

E-mail: hexenal63@gmail.com 